Review

\title{
Growth and Properties of Carbon Microcoils and Nanocoils
}

\author{
Muneaki Hikita *, Robyn L. Bradford and Khalid Lafdi *
}

University of Dayton, 300 College Park, Dayton, OH 45469, USA; E-Mail: bradfordr1@udayton.edu

* Authors to whom correspondence should be addressed; E-Mails: muneaki.hikita@gmail.com (M.H.); klafdi1@udayton.edu (K.L.); Tel.: +1-937-229-2643 (M.H. \& K.L.);

Fax: +1-937-229-3433 (M.H. \& K.L.).

External Editor: Daniele Gozzi

Received: 26 September 2014; in revised form: 2 November 2014 / Accepted: 18 November 2014 / Published: 26 November 2014

\begin{abstract}
Various types of coiled carbon filaments have been synthesized using chemical vapor deposition and other methods. These carbon filaments exhibit unique electrical and mechanical properties due to their versatile shapes and structures. To form coiled shapes, different types of catalyst compositions and reactive gases have been explored. Generally, coiled carbon filaments are classified by coil diameter and shape (e.g., microcoil and nanocoil). In this review, coiled carbon filaments are classified into three growth mechanism categories: (1) bidirectional double helical growth; (2) bidirectional twisted growth; and (3) tip single helical or twisted growth. Next, their synthesis methods and hypothetical growth mechanisms are discussed. Then, their electrical and mechanical properties are listed. Finally, potential applications and uses of coiled carbon filament are mentioned.
\end{abstract}

Keywords: carbon microcoils; carbon nanocoils; CMCs; CNCs; chemical vapor deposition

\section{Introduction}

Carbon is one of the most versatile chemical elements of the periodic table and exists in various allotropic forms including diamond, graphite, and amorphous carbon. Other carbon forms that have garnered considerable attention in research are fullerene, carbon nanotube, graphene, carbon nanodot, and coiled carbon filaments [1-6]. These materials have been studied extensively to elucidate their unique and exciting properties and novel potential applications. Coiled carbon filaments, in particular, 
have been found to possess attractive morphologies, as well as excellent mechanical and electrical properties including superelasticity, low Young's modulus, relatively high electrical conductivity, and good electromagnetic (EM) wave absorption [7-10]. These properties have led to the evaluation of helically shaped filaments with nano and micrometer coil diameters for use as tactile sensors, electromagnetic interference (EMI) shielding, and field emission devices [7,10,11]. In the early years, despite reports by several groups of successfully growing coiled carbon filaments, reproducing published results remained challenging. In 1953, vermicular carbon filaments were found in the deposition of carbon in the brickwork of blast furnaces and were reproduced by iron containing brick by Davis et al. [12]. In 1972, Baker et al. [13] produced twisted carbon filaments with 30-60 nm diameters using nickel particle catalyst. The following year, Boehm reported twisted carbon filaments and double helical filaments by pyrolysis of diluted $\mathrm{Fe}(\mathrm{CO})_{5}$ vapor. This led to a proposed growth mechanism for double helical filaments [14]. In addition, the Motojima research group established a method to synthesize bidirectionally grown double helical carbon filaments or carbon microcoils (CMCs) that were several micrometers in diameter by adding sulfur compound [15]. The Nakayama research group developed tip grown single helical carbon filaments or carbon nanocoils (CNCs) with diameters in the range of several tens to several hundred nanometers using iron-tin based catalysts [6]. Figure 1 illustrates the different varieties of coiled carbon filaments that have been synthesized over the years. Based on growth mode, coiled carbon filaments can be classified into three groups: (1) bidirectionally grown double helical carbon filaments (b-DHCFs) [16]; (2) bidirectionally grown twisted carbon filaments (b-TCFs) [17]; and (3) tip grown single helical carbon filaments (t-SHCFs) [18] or tip grown twisted carbon filaments (t-TCFs) [18]. Structurally, some t-SHCFs and t-TCFs can have hollow cores like multi-walled carbon nanotubes (MWCNTs) [19]. Surface-wise, t-SHCFs and t-TCFs generally have sharp edges. In contrast, b-DHCFs and b-TCFs are smooth. All of these growth modes strongly depend on catalyst and reactive gas compositions.

Figure 1. Different types of coiled carbon filaments: (a) bidirectionally grown double helical carbon filaments (b-DHCFs) [16]; (b) bidirectionally grown twisted carbon filaments (b-TCFs) [17]; (c) tip grown single helical carbon filaments (t-SHCFs) [18]; and (d) tip grown twisted carbon filaments (t-TCFs) [18]. Reprinted with permission from [16-18], Copyright 1999 AIP Publishing LLC, Copyright 2004 Elsevier, and Copyright 2010 Elsevier.

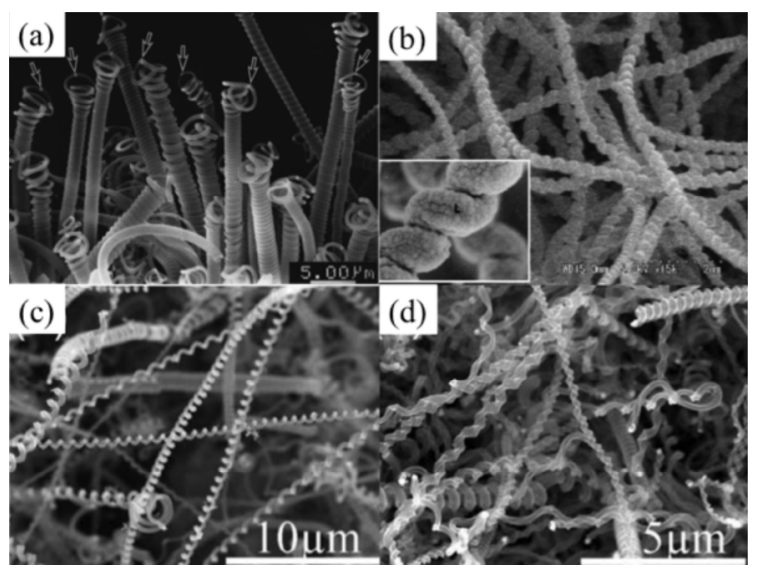




\section{Synthesis}

\subsection{Synthesis of Bidirectionally Grown Double Helical Carbon Filaments}

To synthesize uniform bidirectionally grown double helical carbon filaments (b-DHCFs), a small amount of sulfur or phosphorus additive is introduced with reactive gases. The amount of sulfur or phosphorus additive, the compositions and flow rate of gases and reaction temperature all strongly influence the growth of double helical structures [4,15]. Chemical vapor deposition (CVD) has been the most popular technique used to synthesize b-DHCFs; but other methods have been explored as well, including laser-induced thermal decomposition.

\subsubsection{CVD Method}

The reaction temperature used to synthesize b-DHCFs is usually between 700 and $850{ }^{\circ} \mathrm{C}$ with CVD and depends on the catalyst chemical composition [15]. Like the wide reaction temperature range, choice of catalyst can also vary broadly. For example, Motojima et al. [15] demonstrated that many types of metal powder catalysts such as Ti, Zr, Hf, V, Nb, Ta, Cr, Mo, W, Mn, Co, and Ni could be used to grow b-DHCFs, which Motojima et al. [15] referred to as CMCs. Each of these metal catalysts has a different optimum reaction temperature and amount of sulfur additive gas during CVD. However, it has been shown that it is more effective to grow double helical CMCs with $\mathrm{Ni}$, Ti, or Ta. Using $\mathrm{Ni}$, the average external coil diameter was found to be $5 \mu \mathrm{m}$ and the length of coil after two hours was between 5 and $8 \mathrm{~mm}$ [20]. Although Fe has been used as catalyst for the synthesis of carbon nanofibers and nanotubes, Fe powder with sulfur additive gas was not able to synthesize double helical CMCs [15]. Although hydrogen sulfide $\left(\mathrm{H}_{2} \mathrm{~S}\right)$ gas or thiophene $\left(\mathrm{C}_{4} \mathrm{H}_{4} \mathrm{~S}\right)$ has usually been used to synthesize double helical CMCs, they can be obtained without these additives using $\mathrm{MoS}_{2}$ catalyst. Cobalt and tungsten sulfides also worked without sulfur additive gas [15]. Double helical CMCs grown by nickel sulfide catalyst without sulfur additive gas were reported as well. However, the uniformity of these CMCs was low compared to that of CMCs using thiophene or $\mathrm{H}_{2} \mathrm{~S}$ additive [21]. Yang et al. [22] demonstrated that TiC with $\mathrm{H}_{2} \mathrm{~S}$ gas successfully formed b-DHCFs with an external coil diameter of about $300 \mathrm{~nm}$. Then, Ding et al. [23] synthesized b-DHCFs using phosphorus instead of sulfur. Nickel phosphorus based alloys (Ni-P and Ni-W-P) without hydrogen, sulfur or phosphorus additive gases were used to grow b-DHCFs and triple helical CNCs with 100-300 nm of external coil diameter, as shown in Figure 2. Interestingly, the pre-heat treatment temperature for $\mathrm{Ni}-\mathrm{P}$ alloy catalysts influenced the growth ratio of single helix or twist to double helix. Additionally, it was observed that the b-DHCFs with several hundred nanometer diameters had the same turbostratic graphite structure as b-DHCFs with several micrometer diameters [23,24]. 
Figure 2. TEM images of double helical CNCs grown by Ni-W-P catalyst [23]. Reprinted with permission from [23], Copyright 2004 AIP Publishing LLC.

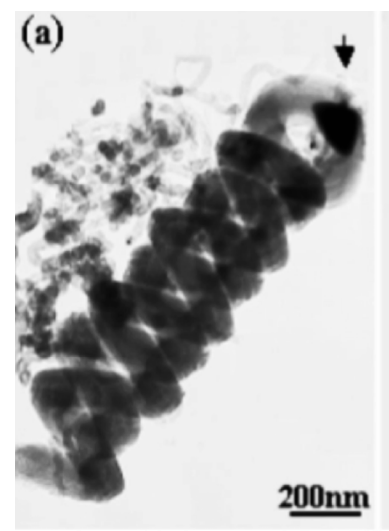

(b)

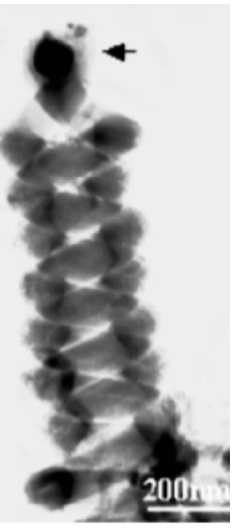

\subsubsection{Other Synthesis Methods}

Other methods in addition to CVD have been used successfully to synthesize coiled carbon filaments as well. For example, Okada et al. [25] reported that b-DHCFs with about $3 \mu \mathrm{m}$ of external coil diameter were synthesized using laser-induced thermal decomposition. With this method, allene $\left(\mathrm{C}_{3} \mathrm{H}_{4}\right)$ gas as carbon source, sulfur hexa-fluoride $\left(\mathrm{SF}_{6}\right)$ as sulfur additive and gaseous ferrocene $\left(\left(\mathrm{C}_{5} \mathrm{H}_{5}\right)_{2} \mathrm{Fe}\right)$ as catalyst were heated by a continuous wave $\mathrm{CO}_{2}$ laser on alumina substrate. Another method employed by Kuzuya et al. [26] led to the synthesis of b-DHCFs with 3-4 $\mu \mathrm{m}$ of external diameter using a plasma and catalyst technology (PACT) reactor. Here, hydrocarbon gas (e.g., methane, propane, ethylene or acetylene) as a carbon source with $\mathrm{H}_{2} \mathrm{~S}$ and $\mathrm{H}_{2}$ gases was decomposed by nitrogen plasma. Afterwards, the decomposed gases were introduced to the nickel catalyst powder on graphite substrate.

\subsection{Bidirectionally Grown Twisted Carbon Filaments}

To synthesize bidirectionally grown twisted carbon filaments (b-TCFs), CVD is usually used at a reaction temperature between 500 and $800{ }^{\circ} \mathrm{C}$ with sulfur or phosphorus additive gas [23,27]. Chen et al. [27] reported growing b-TCFs using Ni catalyst supported on $\mathrm{Al}_{2} \mathrm{O}_{3}$ powder with $\mathrm{H}_{2} \mathrm{~S}$ gas. The external coil diameter was between 100 and $500 \mathrm{~nm}$. Structurally, the b-TCFs were slightly more crystallized than b-DHCFs. Ding et al. [23] demonstrated that Ni-P and Ni-W-P alloys produced not only double helical CNCs, but also b-TCFs with about $100 \mathrm{~nm}$ of external diameter (Figure 3). In contrast, Qin et al. [28,29] reported a low reaction temperature method for the synthesis of b-TCFs without sulfur and phosphorus gas. Qin et al. grew b-TCFs using $\mathrm{Cu}$ catalytic nanoparticles with acetylene gas at $195{ }^{\circ} \mathrm{C}$. The $\mathrm{Cu}$ nanoparticles were prepared by the reduction of copper sulfate with sodium borohydride $[28,29]$. X-ray diffraction (XRD) revealed the b-TCFs non-graphitic structure; and infrared (IR) spectroscopy along with elemental analysis indicated their hydrocarbon composition with $\mathrm{C}$ to $\mathrm{H}$ molar ratios of 1.06 to 1 because of the very low reaction temperature [28]. Nitze et al. [30] synthesized b-TCFs using fullerene supported palladium nanoparticles $\left(\mathrm{Pd}_{2} \mathrm{C}_{60}\right)$ at the reaction temperature between 550 and $600{ }^{\circ} \mathrm{C}$ with acetylene gas and water. The $\mathrm{Pd}_{2} \mathrm{C}_{60}$ was able to selectively grow more b-TCFs than Pd film. Overall, the morphologies of the b-TCFs grown by Ni with sulfur additive gas, $\mathrm{Ni}-\mathrm{P}$ alloys, $\mathrm{Cu}$ nanoparticles, and $\mathrm{Pd}_{2} \mathrm{C}_{60}$ were all quite similar. 
Figure 3. A growth tip of the bidirectionally grown twisted carbon filaments [23]. Reprinted with permission from [23], Copyright 2004 AIP Publishing LLC.

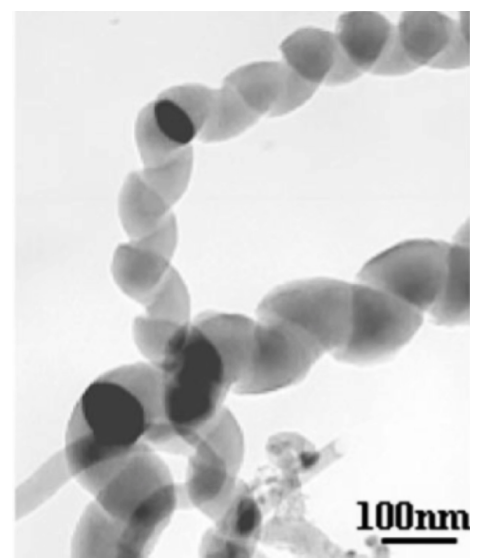

\subsection{Synthesis of Tip Grown Single Helical or Twisted Carbon Filaments}

For the synthesis of tip grown single helical carbon filaments (t-SHCFs), chemical composition, size and uniformity of catalyst play important roles [31-33]. Typically, t-SHCFs are synthesized by CVD using two or more chemical compositions of catalyst with acetylene or methane as carbon source along with argon or helium. For the iron-based catalyst, the reaction temperature was $680-700{ }^{\circ} \mathrm{C}$ [32]. Except in a few reports, sulfur or phosphorus additive with hydrogen gas was not used for the single helical structure [18,22,32].

\subsubsection{Indium, Iron and Tin Based Catalysts}

Zhang et al. [6] discovered that Fe coated indium tin oxide (ITO) could be used as catalyst to synthesize single helical carbon tubule nanocoils. Iron with a thickness of $15 \mathrm{~nm}$ was coated onto a $300 \mathrm{~nm}$ ITO film by vacuum vaporization through shadow masks. The external diameter of the resultant tubules was 30-80 nm (Figure 4). As illustrated in Figure 5, the single helical carbon tubule nanocoil had a more aligned graphite structure than the b-DHCF [6,24]. The interlayer spacing of graphite for single helical carbon tubule nanocoils was $0.33 \mathrm{~nm}[6]$.

Figure 4. TEM micrograph of a single helical carbon tubule nanocoils [6]. Reprinted with permission from [6], Copyright 2000 Japan Society of Applied Physics.

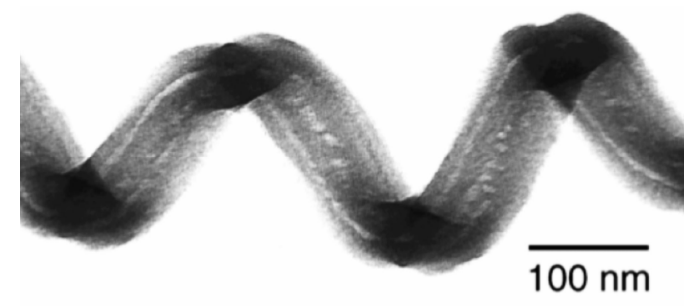


Figure 5. TEM micrographs of (a) bidirectionally grown double helical carbon filament [24] and (b) a single helical carbon tubule nanocoils [6]. Reprinted with permission from [6], Copyright 2000 Japan Society of Applied Physics; Reprinted with permission from [24], Copyright 2004 Elsevier.
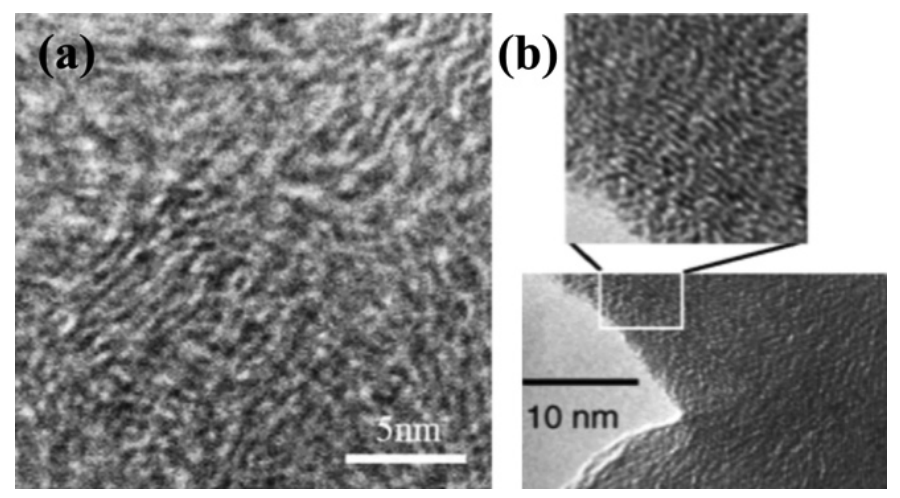

Okazaki et al. [33] grew single helical CNCs using Sn-Fe-In-O catalytic particles synthesized by wet chemical reaction. Iron chloride $\left(\mathrm{FeCl}_{3}\right)$, indium chloride $\left(\mathrm{InCl}_{3}\right)$, and tin chloride $\left(\mathrm{SnCl}_{3}\right)$ aqueous solutions were mixed in appropriate ratios. An ammonium carbonate $\left(\left(\mathrm{NH}_{4}\right)_{2} \mathrm{CO}_{3}\right)$ aqueous solution or base solution was added to the mixture of iron, indium and tin chloride solution to precipitate iron, indium and tin hydroxides simultaneously. The precipitate was rinsed with deionized water, dried at $110{ }^{\circ} \mathrm{C}$, and milled to make a fine powder. This powder was then heated to form $\mathrm{Fe}_{2} \mathrm{O}_{3}, \mathrm{In}_{2} \mathrm{O}_{3}$, and $\mathrm{SnO}_{2}$ by dehydration. The optimum composition ratio of In to $\mathrm{Sn}$ in Fe matrix to grow single helical CNCs was $10 \%-33 \%$ to below $3.3 \%$, but not zero.

\subsubsection{Fe-Sn Oxide Catalyst}

Kanada et al. [19] reported that Fe-Sn oxide could be used to synthesize multi-walled CNCs. Fe-Sn thin film catalyst was prepared using a vacuum arch plasma deposition method. Fe and Sn were uniformly co-deposited on Si substrate using two independent arc plasma guns. An Fe/Sn ratio of 4 to 3 was best for yielding CNC. The Fe-Sn thin film was annealed at $150{ }^{\circ} \mathrm{C}$ in air for $12 \mathrm{~h}$ in order to oxidize the catalyst to prevent Sn from vaporizing during heating. The average coil diameter of CNCs synthesized with the catalyst was $54 \mathrm{~nm}$. As shown in Figure 6, the CNCs had a hollow structure and multi-walled graphene layers.

Li et al. [18] produced single helical CNCs with average coil diameters of 500-900 nm with $\mathrm{Fe}-\mathrm{Sn}-\mathrm{O}$ catalytic particles. The catalytic particles were prepared by sol-gel method using $\mathrm{Fe}_{2}\left(\mathrm{SO}_{4}\right)_{3}$, $\mathrm{FeCl}_{3}$ or $\mathrm{Fe}\left(\mathrm{NO}_{3}\right)_{3}$ as an iron precursor and $\mathrm{SnCl}_{2}$ as a tin precursor. The iron and tin precursors in a molar ratio of 3:1 along with $\mathrm{C}_{6} \mathrm{H}_{8} \mathrm{O}_{7} \mathrm{H}_{2} \mathrm{O}$ were mixed in ethanol. The mixture was heated and stirred at $80{ }^{\circ} \mathrm{C}$ for $3 \mathrm{~h}$ to transform the solution to gel; the gel was then heated in air at $700{ }^{\circ} \mathrm{C}$ to obtain $\mathrm{Fe}-\mathrm{Sn}-\mathrm{O}$ particles. Interestingly, it was observed that the type of iron precursor used had a strong influence on $\mathrm{CNC}$ morphology (i.e., helical or twisted shapes). The shapes for $\mathrm{FeCl}_{3}, \mathrm{Fe}_{2}\left(\mathrm{SO}_{4}\right)_{3}$, and $\mathrm{Fe}\left(\mathrm{NO}_{3}\right)_{3}$ were found to be helical, helical and twisted, and twisted with other shapes, respectively. 
Figure 6. TEM image of multi-walled CNC [19]. Reprinted with permission from [19], Copyright 2008 Japan Society of Applied Physics.

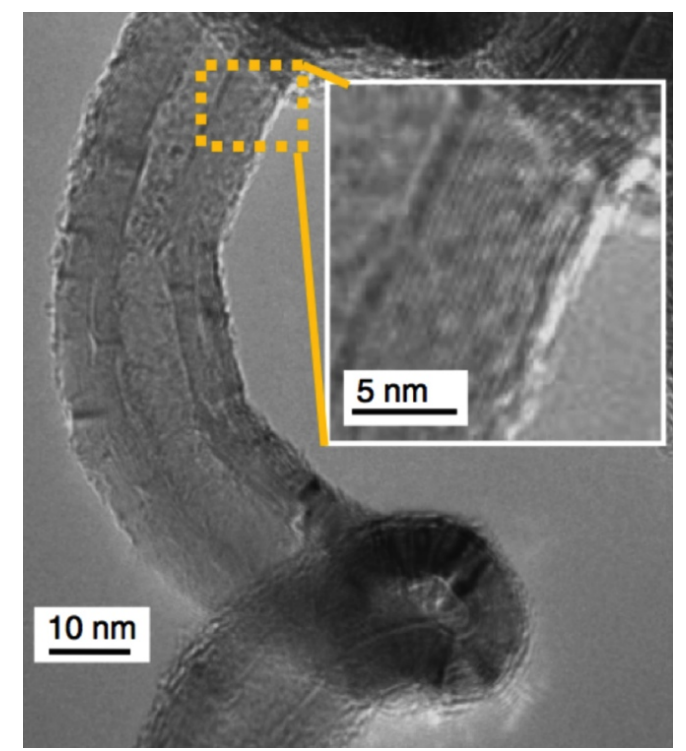

\subsubsection{Fe-Based Alloy Catalysts with Sulfur Additive Gas}

Iron-based alloy (Fe:Ni:Cr = 44:5:1) catalyst with hydrogen sulfide gas can be used to synthesize single helical carbon microcoils, with coil diameters ranging from 0.5 to $3 \mu \mathrm{m}$. On the other hand, nickel-based alloy (Fe:Ni:Cr = 5:44:1) grew double helical CMCs [34]. Fe-Ni-In with thiophene gas was also used to grow single helical CMCs [17]. The twisted ribbon-like carbon filaments in Figure 7 were synthesized by Chen et al. [35] using iron-based alloys $\left(\mathrm{Fe}_{74} \mathrm{Co}_{18} \mathrm{Ni}_{8}\right.$ or $\left.\mathrm{Fe}_{71} \mathrm{Cr}_{18} \mathrm{Ni}_{8} \mathrm{Mo}_{3}\right)$ with $\mathrm{H}_{2} \mathrm{~S}$ gas. The width and thickness of these ribbon-like nanofibers were 100-200 nm and 10-50 nm, respectively. In addition, it should be noted that although sulfur was added, the growth mode with iron-based alloy was from the tip instead of bidirectional.

Figure 7. Representative twisted ribbon-like nanofibers grown by $\mathrm{Fe}_{14} \mathrm{Cr}_{18} \mathrm{Ni}$ catalyst [35].

Reprinted with permission from [35], Copyright 2005 Elsevier.

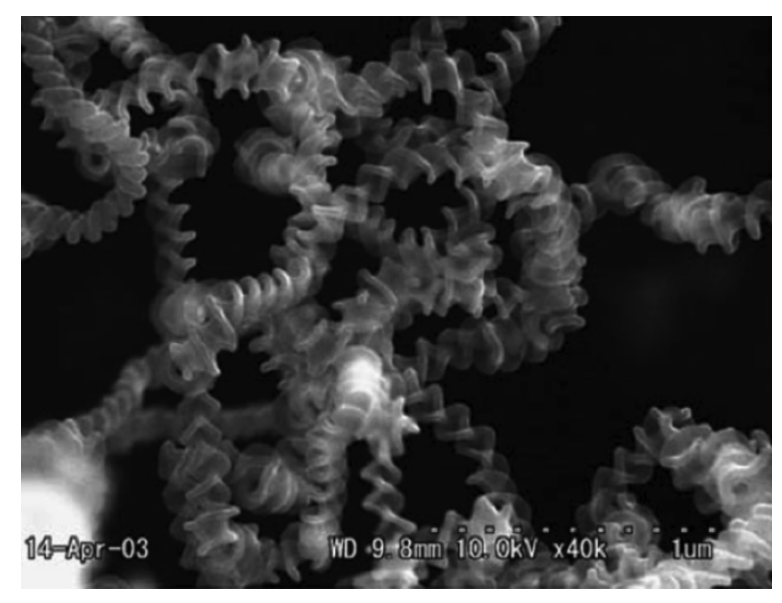




\subsubsection{Sn Catalyst Supported by $\mathrm{BaSrTiO}_{3}$ Substrate}

Sun et al. [36] reported synthesizing single helical CNCs with 200-900 nm of external coil diameter using $\mathrm{Sn}$ on $\mathrm{BaSrTiO}_{3}$ substrate as catalyst. $\mathrm{Sn}$ was introduced in the pits or grain boundary triple junctions of polycrystalline $\mathrm{BaSrTiO}_{3}$ substrate. The catalytic particles on the tip of CNCs consisted of $\mathrm{Sn}, \mathrm{Sr}, \mathrm{Ba}, \mathrm{Ti}$ and $\mathrm{O}$ with a $\mathrm{Sn}: \mathrm{Ba}: \mathrm{Sr}: \mathrm{Ti}: \mathrm{O}$ molar ratio of 1:6:4:10:30 based on quantitative energy dispersive X-ray (EDX) analysis.

\subsubsection{Water Soluble Na-K Catalyst}

Qi et al. [37] successfully grew single helical CNCs using water-soluble, wet chemistry prepared $\mathrm{Na}_{x} \mathrm{~K}_{y}$ catalyst; which involves a less complicated and inexpensive CNC purification process. Sodium hydroxide, potassium hydroxide and citric acid were dissolved in absolute ethanol. The mixture was stirred at $60{ }^{\circ} \mathrm{C}$ for $4 \mathrm{~h}$ and then heated at $80{ }^{\circ} \mathrm{C}$ to form white powder. Next, the powder was heated twice in air at $600{ }^{\circ} \mathrm{C}$ for $4 \mathrm{~h}$ to yield $\mathrm{Na}_{x} \mathrm{~K}_{y}$ catalyst.

\section{Growth Mechanisms}

\subsection{Growth Mechanism of Bidirectionally Grown Double Helical and Twisted Carbon Filaments}

Tip growth has some derivative growth modes related to catalyst composition (Figure 8). Multi-directional carbon filaments were formed on nickel catalysts containing high sulfur coverage [38,39]. Bidirectional growth of carbon filament using $\mathrm{Fe}-\mathrm{Sn}$ catalytic particles was also reported [40]. Audier et al. [41,42] proposed a mechanism for carbon bidirectional growth as illustrated in Figure 9. The dissociative chemisorption of the gas can occur at the emerging line of a subgrain boundary of the metallic bicone catalytic particle. The bicone subgrain boundary is either of the (110) type with a face-centered cubic (FCC) metallic structure, or of the (100) type with a body-centered cubic (BCC) metallic structure. Because of the dislocation, the subgrain boundary was slightly disoriented $\left(1^{\circ}\right.$ to $\left.5^{\circ}\right)$ with respect to the bicone catalyst axis (Figure 9). The diffusion coefficient along a subgrain boundary is about $10^{4}$ times higher than the bulk diffusion coefficient. Therefore, carbon atoms can diffuse very quickly at first into the subgrain boundary, and afterwards symmetrically through both parts of the bicone [41,42]. Chen et al. [43] proposed a growth mechanism for bidirectionally grown double helical carbon filaments (b-DHCFs) synthesized with nickel catalyst and sulfur additive. During growth, a quasi-liquid phase composed of $\mathrm{Ni}-\mathrm{C}-\mathrm{S}-\mathrm{O}$ is formed around rhombohedral $\mathrm{Ni}_{3} \mathrm{C}$ catalyst and extends in two directions to grow bidirectional carbon filaments. The order of magnitude for carbon deposition on Ni crystal planes was $(100)>(111)>(110)$. Since each crystal plane on the surface of rhombohedral $\mathrm{Ni}$ catalyst is different, the ratio of catalytic activity on each crystal face of rhombohedral Ni catalyst determines the degree of curvature for carbon filaments and subsequently the external coil diameters [44]. Growth tips of b-DHCFs and bidirectionally grown twisted carbon filaments (b-TCFs) are shown in Figure 10 [27,44]. At unoptimized reaction temperatures, bidirectionally grown straight carbon filaments were observed (Figure 11) [45]. It was suggested that helical shape of carbon filaments is formed by the rotation of catalyst and the different shapes between b-DHCFs and b-TCFs are attributed to rotation direction of catalysts (Figure 12) [27]. 
Figure 8. Schematic representation of different types of growth observed in carbon filaments [38]. Reprinted with permission from [38], Copyright 1989 Elsevier.

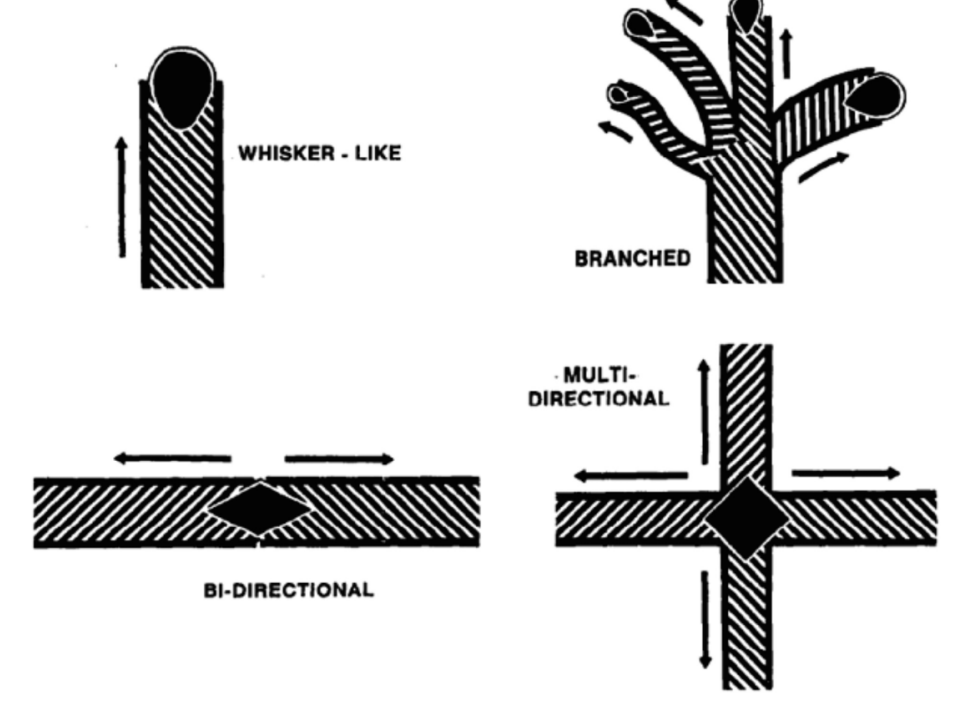

Figure 9. Schematic drawing of (a) bitube formation [41] and (b) disorientation $\left(1^{\circ}\right.$ to $\left.5^{\circ}\right)$ of (110) subgrain boundary with respect to bicone axis [42]. Reprinted with permission from [41,42], Copyright 1985 Elsevier and Copyright 1982 Elsevier.

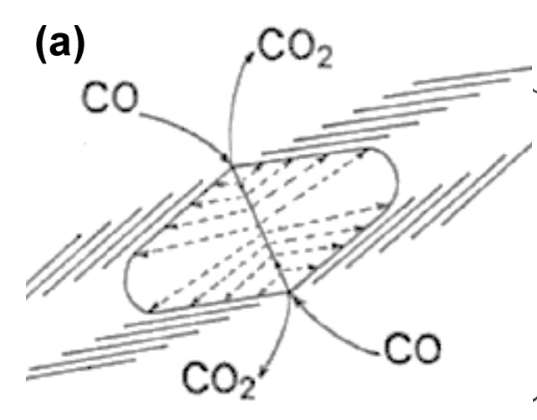

(b)

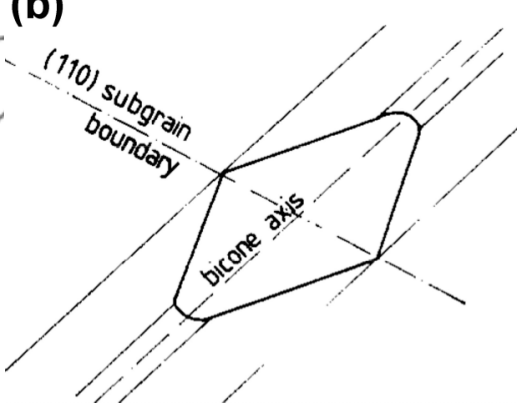

Figure 10. Growth tip of (a) a bidirectionally grown double helical carbon filament (b-DHCF) [44] and (b) a bidirectionally grown twisted carbon filament (b-TCF) [27]. The white tips on the top are the catalytic grains. Reprinted with permission from $[27,44]$, Copyright 2003 Elsevier and Copyright 2002 Elsevier.

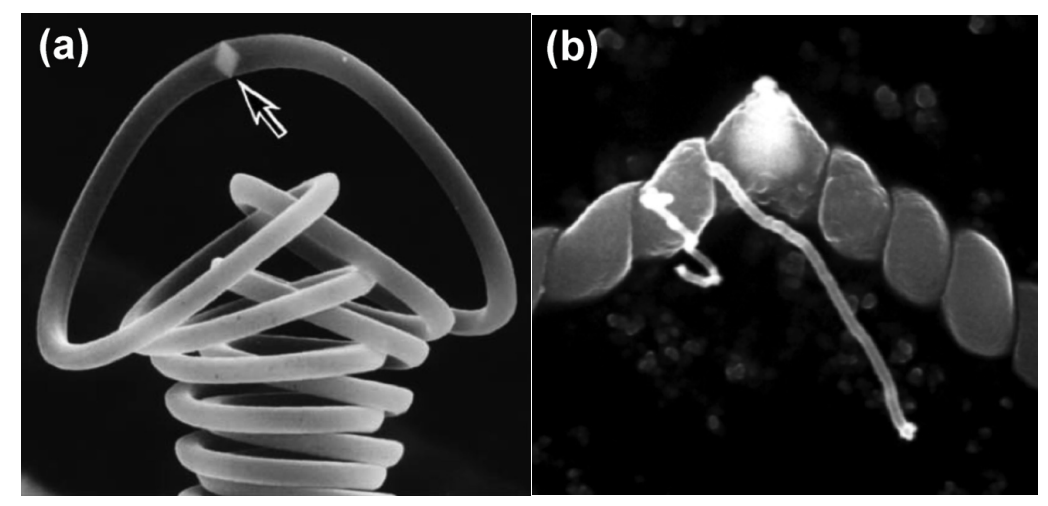


Figure 11. SEM image of bidirectionally grown straight carbon filaments at $953 \mathrm{~K}$ [45]. Reprinted with permission from [45], Copyright 2005 Elsevier.

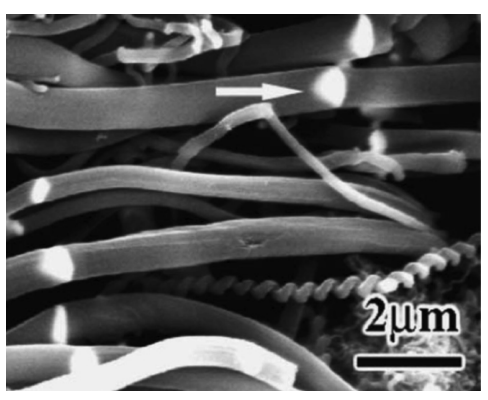

Figure 12. Schematic diagram of two rotation directions for catalysts during growth of (a) bidirectionally grown double helical carbon filament (b-DHCF) and (b) bidirectionally grown twisted carbon filament (b-TCF) [27]. Reprinted with permission from [27], Copyright 2003 Elsevier.

(a)

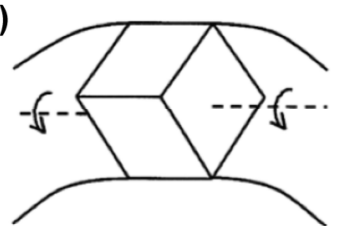

(b)

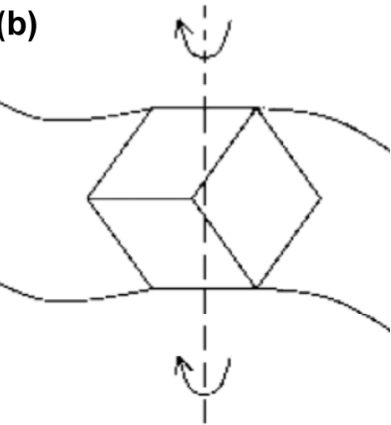

\subsection{Growth Mechanism of Single Helical and Twisted Carbon Filaments}

Okazaki et al. [33] proposed a growth mechanism for single helical CNCs synthesized with $\mathrm{Sn}-\mathrm{Fe}-\mathrm{In}-\mathrm{O}$ catalyst. With this method, the composition of the catalytic particle at the tip of the coiled filament is not uniform. When the composition of Sn is small, Sn can be localized in the catalyst, thus forming the composition gradient of $\mathrm{Sn}$ in Fe matrix. The deposition rate of carbon on a high-localized part of Sn is slower than that on a low-localized part of Sn. As shown in Figure 13, the coiled filament is formed due to a composition gradient of $\mathrm{Sn}$ between the inner and outer sides of the coils. In contrast to this growth mechanism, a uniform distribution of $\mathrm{Sn}$ in the $\mathrm{Sn}-\mathrm{Fe}$ catalytic nanoparticle on the tip of a CNC was reported using energy dispersive spectroscopy (EDS) in the TEM (Figure 14) [46]. Gohara et al. [47] grew CNCs with Fe-Sn catalyst and studied the growth rate of CNCs using in situ optical microscopy. The Growth rate of CNCs was much higher than that of non-coiled carbon filaments; and the activation energies for the growth of CNCs and non-coiled carbon filaments were $0.5 \mathrm{eV}$ and $1.1 \mathrm{eV}$, respectively. According to EDX results, chemical compositions of catalysts for CNCs and non-coiled carbon filaments were Fe-Sn and only Fe, respectively. Therefore, Sn within Fe matrix 
increased growth rate of carbon filaments [47]. Hikita et al. [48] investigated the growth kinetics of CNCs synthesized with $\mathrm{Sn}-\mathrm{Fe}-\mathrm{O}$ catalyst using an in situ method with a thermogravimetric analyzer. Using a one dimensional growth model to analyze results, they suggested that the diffusion coefficient of carbon in $\mathrm{Fe}_{x} \mathrm{Sn}_{y}$ alloy catalyst $\left(2.8 \times 10^{-13} \mathrm{~m}^{2} \cdot \mathrm{s}^{-1}\right)$ was a little higher than that of $\gamma$-Fe $\left(2.0 \times 10^{-13} \mathrm{~m}^{2} \cdot \mathrm{s}^{-1}\right)$ because $\mathrm{Sn}-\mathrm{Fe}-\mathrm{O}$ catalyst was reduced by carbon and defects were created during the reaction [48]. Duan et al. [49] proposed that an asymmetric catalyst shape causes a helical structure as illustrated in Figure 15. Nitze et al. [30] proposed that a hemisphere-like shape of catalyst and the block of carbon feed on a flat part of the catalyst are important factors for growth of b-TCFs (Figure 16). These factors can cause a gradient of carbon diffusion rates between the inner and outer carbon filament and subsequently form curved or helical filament. This reasoning might also explain the growth of b-DHCFs.

Figure 13. Schematic of carbon nanocoils and fiber grown from various Sn compositions. (A-C) are carbon nanocoils and a carbon fiber grown from catalysts with small, medium and large Sn compositions, respectively. The darker part of the catalyst particle represents the area where $\mathrm{Sn}$ is included. $V_{1}$ and $V_{2}$ are the extrusion velocities of the carbon network at the outer and inner part of the carbon nanocoils and fiber, respectively [33]. Reprinted with permission from [33], Copyright 2005 American Chemical Society.

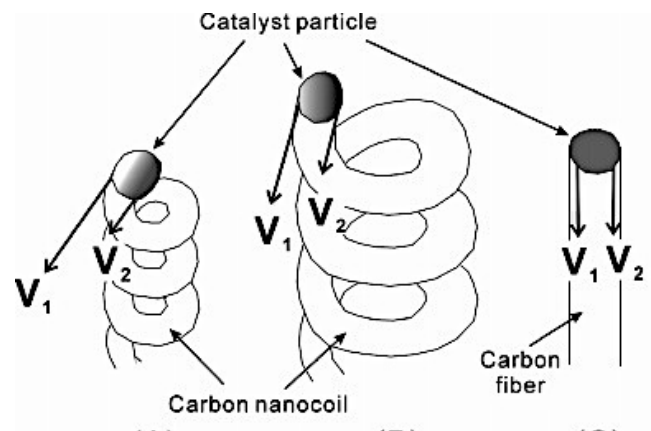

(A)

(B)

(C)

Figure 14. EDS mapping of (a) one single helical CNC and the tip nanoparticle; and images showing the elemental distribution of (b) carbon; (c) iron; and (d) tin [46]. Reprinted with permission from [46], Copyright 2008 John Wiley and Sons.
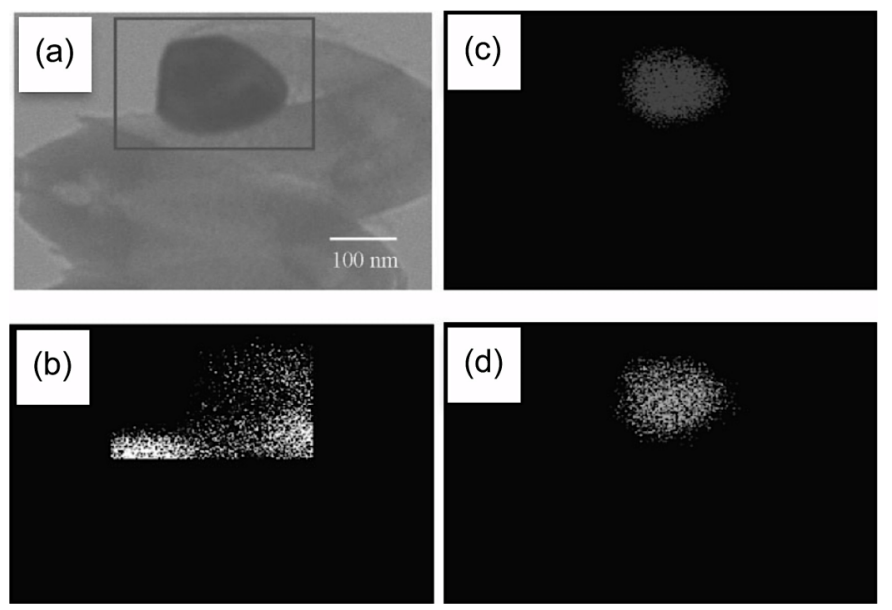
Figure 15. Schematics of growth of filaments from symmetric catalysts (a,b) and asymmetric catalysts (c,d) [49]. Reprinted with permission from [49], Copyright 2010 Elsevier.
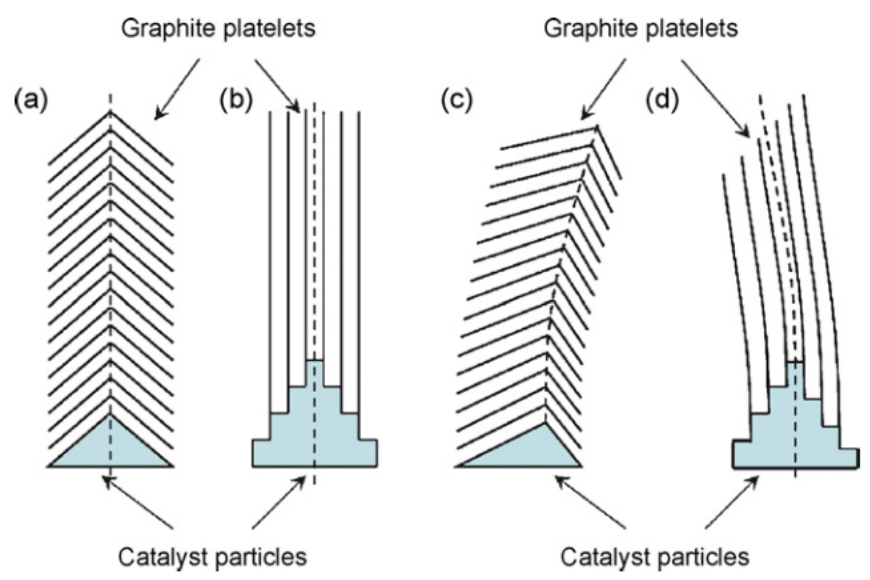

Figure 16. Drawings of the two-dimensional b-TCF growth model with hemisphere-like catalyst and feedstock blocking [30]. Reprinted with permission from [30], Copyright 2011 Elsevier.

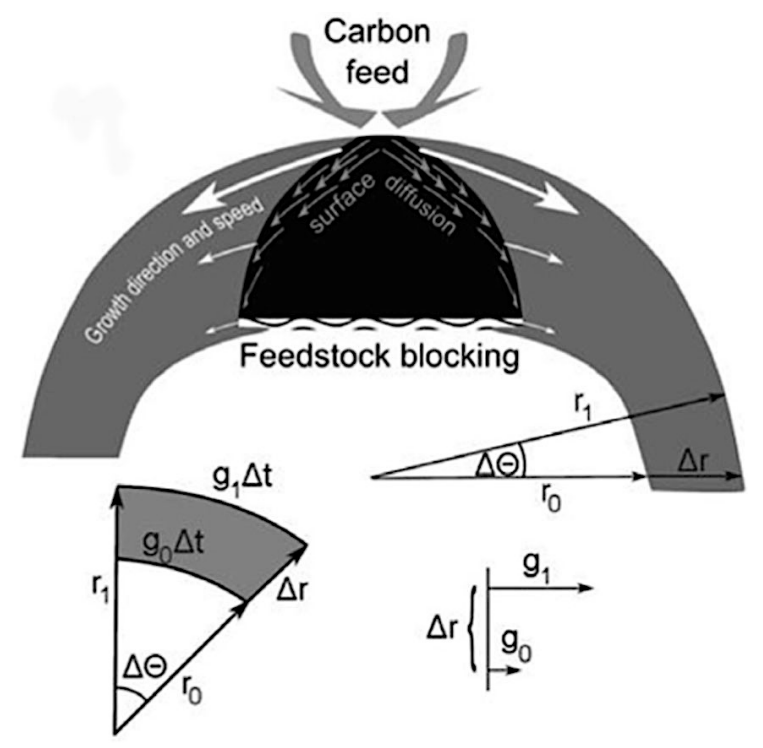

\section{Properties}

\subsection{Electrical Properties}

The electrical conductivities for a bidirectionally grown double helical carbon filament (b-DHCF) with a $5 \mu \mathrm{m}$ diameter along its helix and a tip grown single helical carbon filament (t-SHCF) with a $196 \mathrm{~nm}$ diameter and $1.5 \mathrm{um}$ coil length were 30-50 S/cm and $180 \mathrm{~S} / \mathrm{cm}$, respectively [8,50]. These helical carbon filaments have lower electrical conductivities than pyrolytic graphite (2000-4000 S/cm) [51], and b-DHCFs generally have a lower electrical conductivity than t-SHCFs because of their crystallinities (Figure 5) [6,19,24,28]. Fujii et al. [52] reported that the electrical conductivity of double helical CMCs increased about 10 -fold by heat treatment for $6 \mathrm{~h}$ at $3000{ }^{\circ} \mathrm{C}$ in Ar atmosphere. As shown in Figure 17, heat treated CMCs at $3000{ }^{\circ} \mathrm{C}$ were well graphitized [24]. Katsuno et al. [53] reported impedance $|Z|$ 
and phase angle $\theta$ of a double helical CMC with diameter of $5 \mu \mathrm{m}$ and coil length of $1 \mathrm{~mm}$ (Figure 18). As illustrated, impedance increased with extension of CMCs and decreased with frequency above $1 \times 10^{4} \mathrm{~Hz}$. Impedance and phase angle results suggest that the response of double helical CMCs is equivalent to a resistor-capacitor (RC) parallel circuit; and that the inductance of double helical CMCs is negligible at least in the range between $1 \times 10^{2}$ and $1 \times 10^{5} \mathrm{~Hz}$. As a typical phenomenon of conductive coils, the induction of electromotive force of double helical CMCs in an alternating magnetic field was reported by Kato et al. [54].

Figure 17. TEM image of heat-treated double helical $\mathrm{CMC}$ at $3000{ }^{\circ} \mathrm{C}$ in an inert gas for 6 h [24]. Reprinted with permission from [24], Copyright 2004 Elsevier.

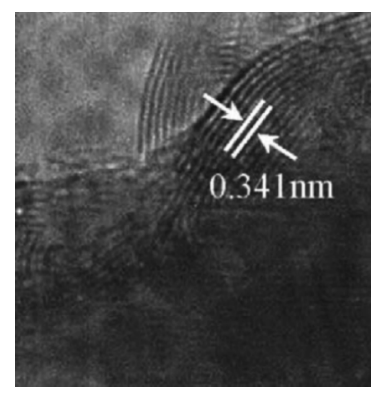

Figure 18. Dependence of (a) impedance $|Z|$ and (b) phase angle $\theta$ on frequency as a function of extension for a pure CMC [53]. Reprinted with permission from [53], Copyright 2007 Elsevier.

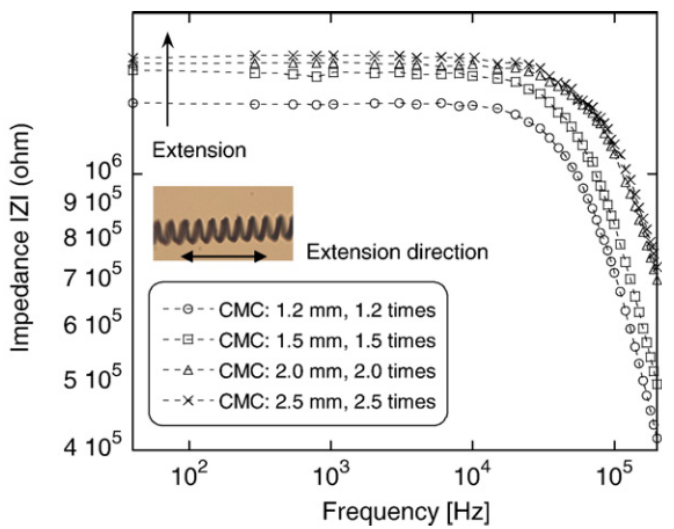

(a)

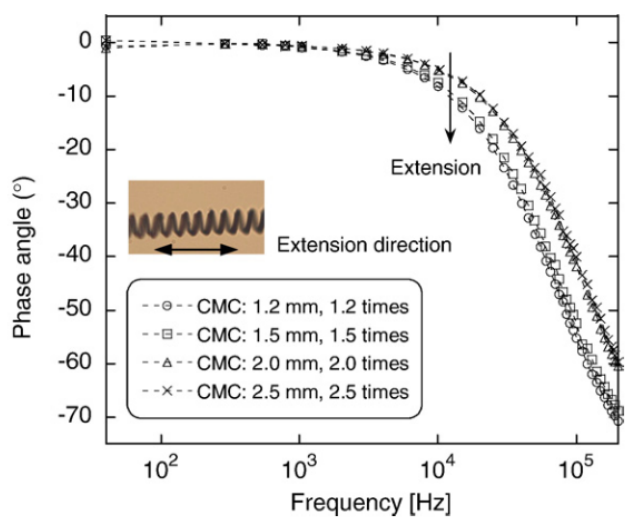

(b)

\subsection{Mechanical Properties}

Young's moduli of single helical tubule CNCs were measured by Hayashida et al. [8] The CNCs were prepared using Fe-coated ITO catalyst and the external coil diameters used for measurements ranged from 144 to $830 \mathrm{~nm}$. For testing, one CNC grown on the edge of a substrate was attached to the tip of a Si cantilever. The cantilever tip was moved to extend the CNC. Hayashida et al. found Young's moduli of single helical CNCs to be $\sim 0.1 \mathrm{TPa}$ and independent of external coil diameter. The shear modulus of single helical tubule CNCs synthesized using Fe-coated ITO catalyst was $2.5 \pm 0.4$, $2.3 \pm 0.4$ or $2.1 \pm 0.3 \mathrm{GPa}$, depending on the estimated inner diameter of the tubule [55]. Chang et al. [9] 
reported shear moduli for double helical CMCs prepared by Fe-catalyzed decomposition of ethanol. The external coil diameter, filament diameter range, pitch and length of the CMCs were $7 \mu \mathrm{m}, 100-250 \mathrm{~nm}$, $2.8 \mu \mathrm{m}$, and $70 \mu \mathrm{m}$, respectively. The shear moduli of these CMCs were $3 \pm 0.2 \mathrm{GPa}$ based on the measurement of the spring constant of the CMC using atomic force microscopy. Yonemura et al. [56] investigated the fracture of $\mathrm{CNCs}$ grown by $\mathrm{Fe}-\mathrm{Sn}$ catalyst. The coil radius and filament diameter were $0.7-0.9 \mu \mathrm{m}$ and $0.3-0.6 \mu \mathrm{m}$, respectively. The average starch ratio of CNCs on the point of fracture was $\sim 150 \%$ and fracture was attributed to stress generated on the inner edge of the helical filament.

\section{Applications}

\subsection{Electromagnetic Interference Shielding}

Due to their coiled shape, coiled carbon filaments have been expected to have an excellent electromagnetic absorption property. Motojima et al. [10] reported 12-110 GHz electromagnetic (EM) wave absorption of double helical CMC/polyurethane. As illustrated in Figure 19, the EM wave absorption property of this CMC composite was compared to other types of carbon composites. The size of the composite materials was $150 \times 150 \mathrm{~mm}^{2}$ with thicknesses of 3.5 to $4.6 \mathrm{~mm}$. The average reflection loss for the CMC composite was higher than straight vapor grown carbon fiber and other carbon powders. The effect of different weight percentages of CMC in polyurethane strongly influenced reflection loss (Figure 20). The tendency of reflection loss changed dramatically around $1-2 \mathrm{wt} \%$ and reflection loss was not improved above $2 \mathrm{wt} \%$ [10].

Figure 19. Reflection loss of different carbon materials (3wt\%) in polyurethane: (a) CMCs; (b) straight vapor grown carbon fibers and (c-e) different types of carbon powders [10]. Reprinted with permission from [10], Copyright 2003 AIP Publishing LLC.

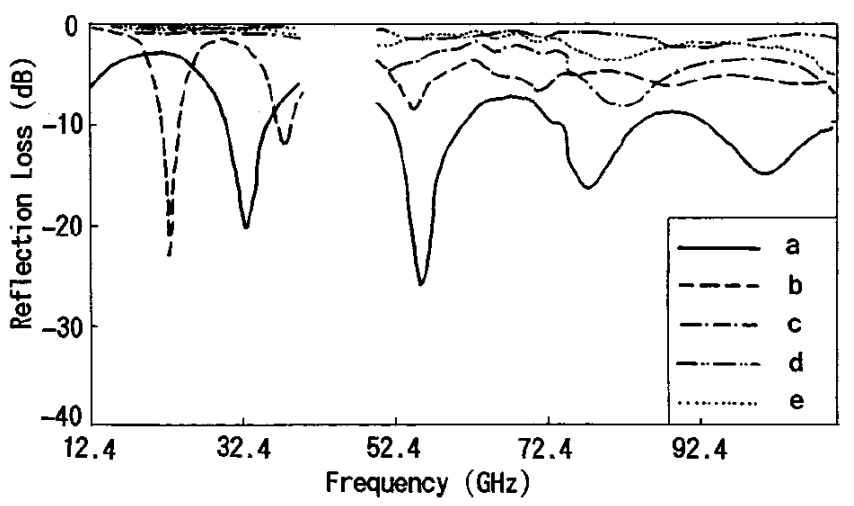

At higher concentrations of filler (20 wt $\%$ in epoxy), Chen et al. [57] observed that double helical CMC composites had a narrow adsorption range around $900 \mathrm{MHz}$. To broaden the absorption range, CMCs were coated with carbon by pyrolysis of methane. This coated CMC composite ( $20 \mathrm{wt} \%$ in epoxy) had a wide absorption range between 500 and $1000 \mathrm{MHz}$ [57]. Tang et al. [58] reported 2-18 GHz EM wave absorption for composites with $35 \mathrm{wt} \%$ of twisted carbon nanofibers in paraffin and different thicknesses of 1, 1.2 and $1.5 \mathrm{~mm}$. As shown in Figure 21, the composites had the highest reflection loss peak around $14 \mathrm{GHz}$. Additionally, note that occurrence of reflection loss peaks decreased with 
increasing composite thickness. It was, thus, concluded that it is possible to control the reflection loss peak by changing composite thickness [58].

Figure 20. Effect of CMC weight percentage in polyurethane matrix [10]. Reprinted with permission from [10], Copyright 2003 AIP Publishing LLC.

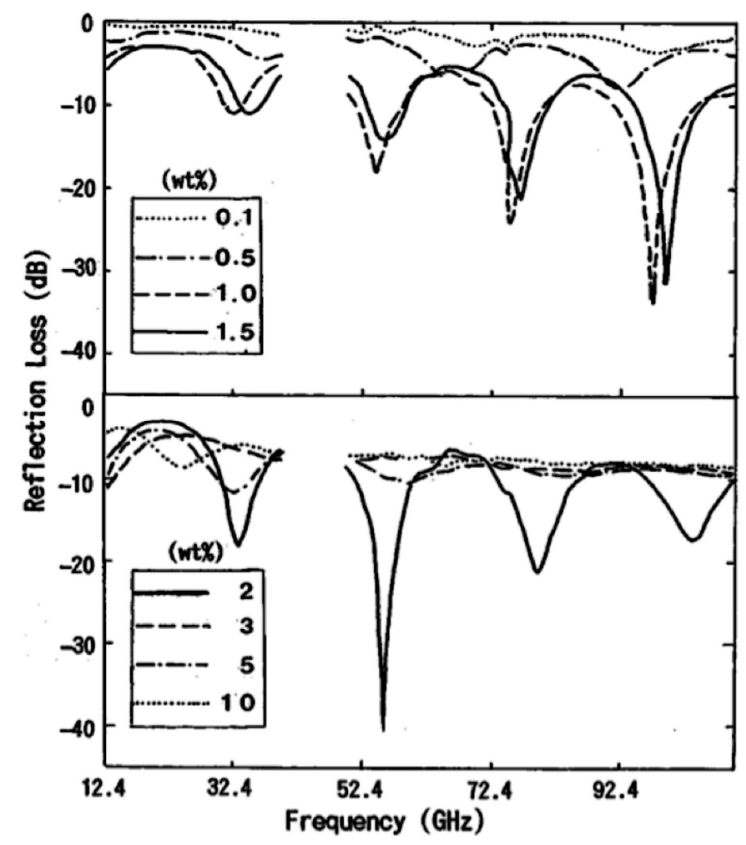

Figure 21. The reflection loss of different thicknesses of twisted carbon filament composites [58]. Reprinted with permission from [58], Copyright 2008 American Chemical Society.

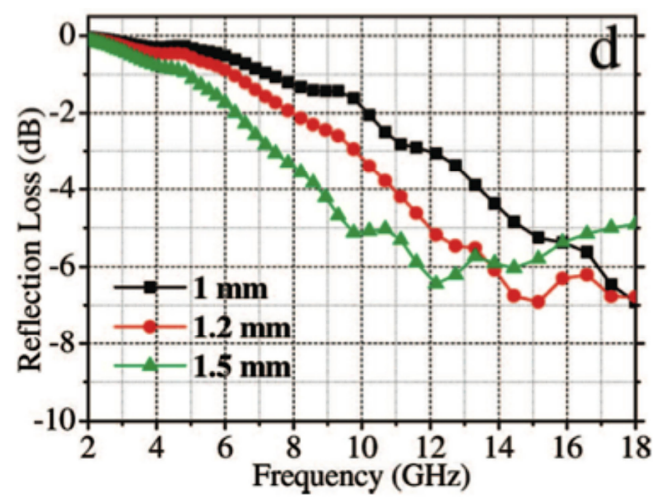

\subsection{Tactile Sensor}

It was demonstrated that double helical CMCs in polysilicone matrix could be used as a tactile sensor. Motojima et al. [59] and Yang et al. [7] investigated the responses of inductance $(L)$, capacitance $(C)$ and resistance $(R)$ for double helical $\mathrm{CMC}$ /polysilicone composites under different loads. Their results, presented in Figure 22, indicate the changes of $L, C$ and $R$ with applied load [7]. The $C$ and $R$ increased and $L$ decreased when load was applied [59]. Furthermore, the changes of $L, C$ and $R$ for composites with CMCs oriented in one direction were found to be much more sensitive than composites with randomly oriented CMCs [7]. 
Figure 22. Changes of $L, C$ and $R$ parameters when different loads were applied to the $5 \mathrm{wt} \% \mathrm{CMC} /$ polysilicone sensor with a $10 \times 10 \times 1 \mathrm{~mm}^{3}$ size [7]. Reprinted with permission from [7], Copyright 2006 IOP Publishing.

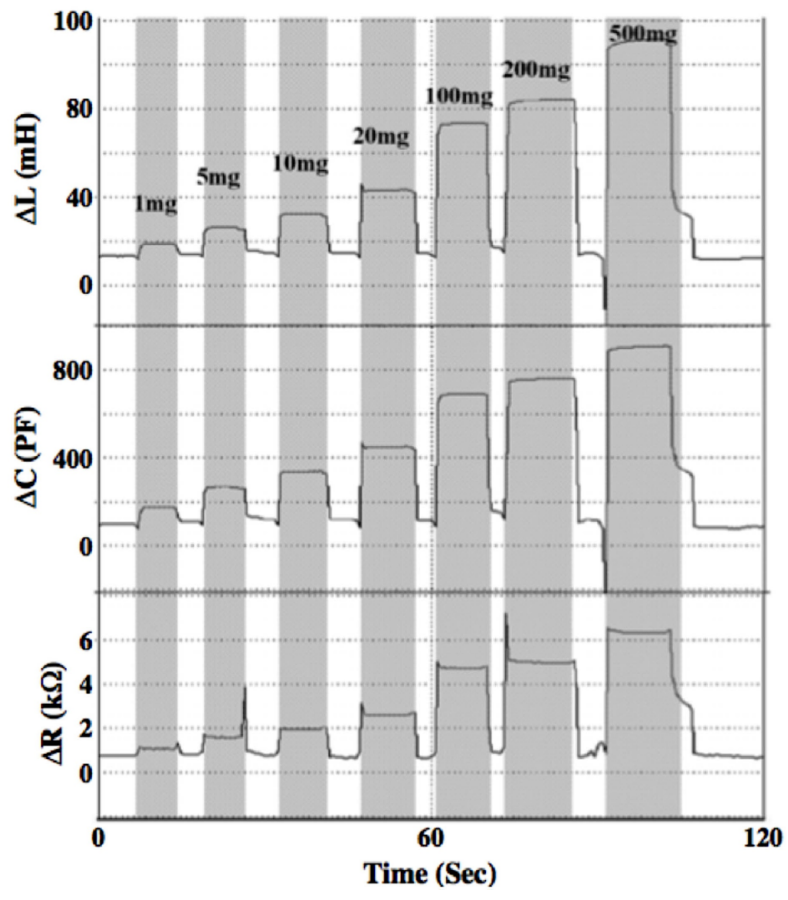

Chen et al. [60] extended this research by investigating the effects of composite thickness on impedance. This was done by using $10 \times 10 \mathrm{~mm}^{2}$ composites of $7 \mathrm{wt} \% \mathrm{CMC}$ uniformly dispersed in soft polysilicone with thicknesses of 3, 5, and $7 \mathrm{~mm}$. Impedance increased with applied load; and thickness influenced sensitivity and the maximum range of applied load [60]. Katsuno et al. [53] reported the impedance and phase angle changes of $5 \mathrm{wt} \%$ double helical $\mathrm{CMC} /$ silicone rubber composite $\left(6 \times 6 \times 2 \mathrm{~mm}^{3}\right)$ under different loads. Low loads resulted in impedance changes that were sensitive to low frequencies (up to $1 \times 10^{3}$ ). On the other hand, large phase angle shifts were observed for low loads in the frequency range of $10^{3}-10^{4} \mathrm{~Hz}$, indicating that the CMC composite was more sensitive to extension than $\mathrm{CMC}$, as shown in Figure 18 in Electrical Properties of single carbon microcoil [53].

\subsection{Effect of CMCs on Composite Tensile Strength}

The tensile strength of double helical CMC and PAN-based carbon fiber (CF) composites was tested by Yoshimura et al [61]. The external coil diameter and length of the CMCs were 1-10 $\mu \mathrm{m}$ and one to several hundred $\mu \mathrm{m}$, respectively. For the CFs, the diameter and length were $7 \mu \mathrm{m}$ and $46 \mu \mathrm{m}$, respectively. To improve wettability in epoxy resin, the surface of the CMCs and CFs were oxidized by $60 \%$ nitric acid at room temperature. The tensile strengths of $6 \mathrm{vol} \% \mathrm{CMCs}$ and $6 \mathrm{vol} \% \mathrm{CFs}$ in epoxy resin with low tensile strength $(0.17 \mathrm{MPa})$ were increased to 0.52 and $0.97 \mathrm{MPa}$, respectively. This showed that CMCs could reinforce composites more than CFs because the CMCs were well grabbed in the resin during extension. On the downside, CMCs could not improve the mechanical properties of epoxy resin with high tensile strength (49 MPa), unlike CFs [61]. 


\subsection{Functionalization of Coiled Carbon Filaments}

Morohashi et al. [62] demonstrated grafting of polymers onto the surface of double helical CMCs to improve dispersion in solvent and prevent aggregation of CMCs [57,58]. CMCs coated with copolymer of vinyl ferrocene with methyl methacrylate or styrene were well dispersed in THF (tetrahydrofuran), toluene and 1,4-dioxane [62]. Carboxyl group functionalized CMCs were prepared using nitric acid and then coated with poly(ethylene glycol) (PEG) or poly(isobutyl vinyl ether) (IBVE). The PEG-coated CMCs were dispersed in water and poly-IBVE-coated CMCs were well dispersed in silicone rubber [63]. Bi et al. [64,65] demonstrated nickel-phosphorus (Ni-P) coating on the surface of double helical CMCs (Figure 23) using an electroless plating process to add magnetic properties. The crystalline size and uniformity of coating could be controlled by the ratio of $\mathrm{P}$ and the deposition rate. The $\mathrm{Ni}$-coated CMCs had a smaller permittivity and a larger permeability than non-coated CMCs in the frequency range of 8.2-12.4 GHz. The microwave absorption of Ni-coated CMCs was attributed to both dielectric and magnetic losses because of the magnetic property of Ni coating $[64,65]$.

Figure 23. SEM image of a Ni-P coated CMC [65]. Reprinted with permission from [65], Copyright 2009 Elsevier.

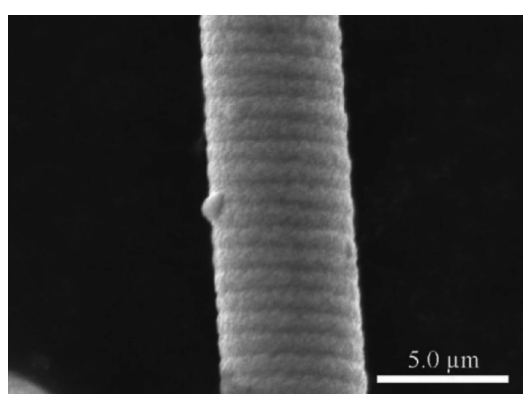

Hikita et al. [66] reported an optical property of octadecylamine (ODA) functionalized CMCs. As shown in Figure 24, ODA functionalized CMCs emitted fluorescent light with a peak of $\sim 423 \mathrm{~nm}$ using a $350 \mathrm{~nm}$ excitation light source. This occurred by passivation on the surface of the CMC turbostratic structure with ODA [66].

Figure 24. UV/Vis absorption (ABS) and fluorescence emission (FLSC, $350 \mathrm{~nm}$ excitation) spectra of ODA functionalized CMCs in isopropyl alcohol (solid curves). In addition, shown for comparison are the non-emissive, acid-treated CMCs without ODA (dashed curve) [66]. Reprinted with permission from [66], Copyright 2014 AIP Publishing LLC.

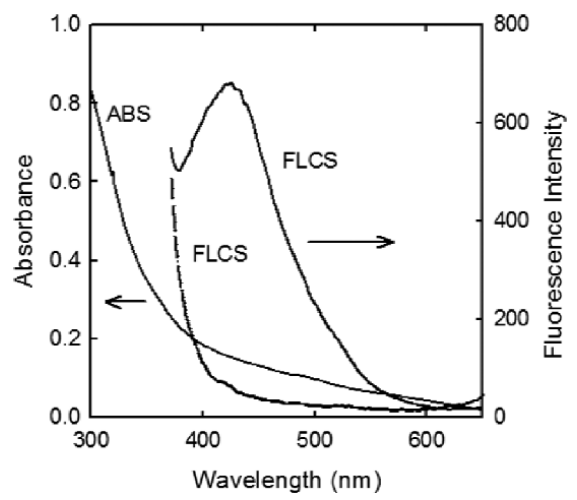




\subsection{Synthesis of Helical Oxide Filaments Using Helical Carbon Filaments as Templates}

Oxide helical filaments or tubes were synthesized using CMCs or CNCs as templates. Motojima et al. [67] reported helical $\mathrm{TiO}_{2}$ filaments using double helical CMCs. A sol-gel method was used to make a $\mathrm{TiO}_{2}$ coating on the surface of CMCs. $\mathrm{TiO}_{2}$-coated CMCs were heated in air at $500{ }^{\circ} \mathrm{C}$ for $2 \mathrm{~h}$ to remove $\mathrm{CMC}$ templates to obtain helical $\mathrm{TiO}_{2}$ filaments (Figure 25) [67].

Figure 25. SEM image of a $\mathrm{TiO}_{2}$ microcoil obtained using a double helical CMC template [67]. Reprinted with permission from [67], Copyright 2003 Elsevier.

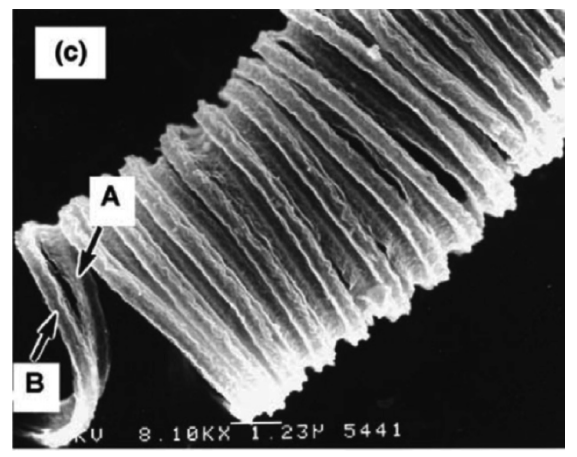

Qin et al. [68] demonstrated growth of helical oxide nanotubes composed of $\mathrm{Al}_{2} \mathrm{O}_{3}, \mathrm{SiO}_{2}, \mathrm{HfO}_{2}$ or $\mathrm{ZnAl}_{2} \mathrm{O}_{4}$ using twisted carbon nanocoils as templates (Figure 26). Each oxide was deposited on CNC templates with an atomic layer deposition. These templates were then removed by oxidation in air at $500{ }^{\circ} \mathrm{C}$ for $1 \mathrm{~h}[68]$.

Figure 26. TEM images of helical nanotubes after removal of CNC templates: (a) $\mathrm{SiO}_{2}$; (b) $\mathrm{TiO}_{2}$ and (c) $\mathrm{HfO}_{2}$ nanotubes. Insets show the diffraction patterns of selected areas of each nanotube [68]. Reprinted with permission from [68], Copyright 2010 John Wiley and Sons.

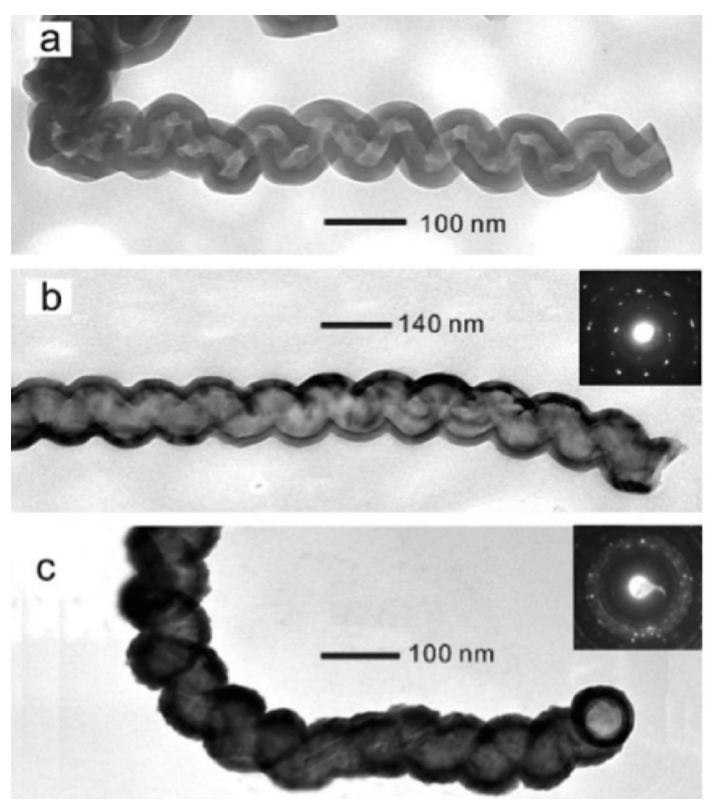




\subsection{Supercapacitor and Fuel Cell}

Rakhi et al. [69] reported that $\mathrm{RuO}_{2}, \mathrm{MnO}_{2}$ or $\mathrm{SnO}_{2}$ nanoparticle coatings and conductive polymer coatings enhanced the electro-chemical capacitance of CNCs. The specific capacitances of $\mathrm{RuO}_{2} / \mathrm{CNC}_{\text {, }}$ $\mathrm{MnO}_{2} / \mathrm{CNC}$ and $\mathrm{SnO}_{2} / \mathrm{CNC}$ composites were 311, 212, and $134 \mathrm{~F} / \mathrm{g}$, respectively. Specific capacitance was superior to that of metal oxide dispersed multi-walled carbon nanotube composite [69]. Specific capacitances of polyaniline coated CNCs and polypyrrole coated CNCs were 360 and $202 \mathrm{~F} / \mathrm{g}$, respectively [70]. Nitze et al. [71] and Suda et al. [72] reported that CNCs efficiently work as a catalyst support for fuel cell anode and cathode [71,72]. Pd nanoparticle coated b-TCFs as anode in formic acid fuel cells could generate $300 \mathrm{~mA} / \mathrm{mg}$ of $\mathrm{Pd}$ at room temperature and showed higher power density than Pd nanoparticle coated MWCNTs [71]. PtRu nanoparticle coated t-SHCFs as anode in direct methanol fuel cells showed higher current than other carbon nanonarticles (Vulcan and Arc-Black) coated with PtRu nanoparticles. Moreover, the power density of Pt nanoparticle coated t-SHCFs as cathode was 1.2 times higher than that of $\mathrm{Pt}$ nanoparticle coated Vulcan and 1.6 times higher than that $\mathrm{Pt}$ nanoparticle coated Arc-Black [72].

\subsection{Hydrogen Storage}

Furuya et al. [24] demonstrated adsorption of hydrogen on double helical CMCs, which had 0.1-10 mm coil length, $1-5 \mu \mathrm{m}$ coil diameter, $0.1-0.5 \mu \mathrm{m}$ coil pitch and about $100 \mathrm{~m}^{2} / \mathrm{g}$ specific surface area. Adsorption of hydrogen was performed under $10 \mathrm{MPa}$ hydrogen gas at liquid nitrogen temperature. Due to the turbostratic structure of CMCs, they adsorbed $0.12-0.16$ mass \% hydrogen, which was 3-4 times larger than the amount of hydrogen commercially activated carbons adsorb [24].

\subsection{Field Emission}

Pan et al. [11] reported the field emission property of single helical tubule CNCs. A field emission current density of $1 \mathrm{~mA} / \mathrm{cm}^{2}$ was achieved at $340 \mathrm{~V}$ and a decrease of the current density was not observed for $100 \mathrm{~h}$. Compared to carbon nanotubes (CNTs), CNCs have a large number of edges on their surfaces due to their coiled shape. This explains why electron emission from CNCs was more uniform than CNT emission [11].

\section{Summary and Outlook}

Coiled carbon filaments have one of the most attractive shapes and unique electrical and mechanical properties due to turbostratic carbon structure or well-graphitized structure. Generally, coiled carbon filaments have been classified by external coil diameters (e.g., carbon microcoils and carbon nanocoils). However, classifying coiled carbon filaments by size can be misleading in terms of their properties and growth mechanisms. To address this concern, in this review, coiled carbon filaments were classified by growth type and categorized into three groups: (1) bidirectionally grown double helical carbon filaments (b-DHCFs); (2) bidirectionally grown twisted carbon filaments (b-TCFs); and (3) tip grown single helical carbon filaments (t-SHCFs) and tip grown twisted carbon filaments (t-TCFs). Generally, sulfur or phosphorous plays an important role for bidirectional growth, and catalyst composition is significant for tip grown single helical or twisted growth. Some t-SHCFs and t-TCFs have hollow structures like 
MWCNTs, but hollow structures of b-DHCFs and b-TCFs have not been reported. This article also presented electrical and mechanical properties of various coiled carbon filaments. For example, it was reported that types of helical carbon filaments (b-DHCFs and t-SHCFs) had lower electrical conductivities than pyrolytic graphite; and that b-DHCFs generally had lower conductivities than t-SHCFs. With regard to mechanical properties, Young's and shear moduli results were presented for single helical tubule CNCs synthesized from Fe-coated ITO catalyst. And shear moduli for double helical CMCs formed by Fe-catalyzed decomposition of ethanol was discussed. Although their growth mechanisms are not yet fully understood, many synthesis methods have been developed to obtain and study the properties, beauty, and unique shapes of coiled carbon filaments. However, there remains an urgent need to pursue fundamental research into catalytic activity and growth kinetics to further our understanding of their growth processes. Further growth analysis of coiled carbon filaments will prove useful as they are being investigated for several interesting applications including EMI shielding, tactile sensors, supercapacitors, fuel cells and hydrogen storage devices. To fully assess coiled carbon filaments for such uses, it is also vital to advance synthesis methods to scale-up production, lower costs, and to achieve reproducibility in terms of uniform coil shape. Another urgent need is for the coil community to establish clear guidelines for shape categorization. Currently, there is no consensus on a structure classification scheme and this can lead to misunderstandings when trying to compare coiled carbon filaments synthesized by different research groups. The authors anticipate that this review paper will continue to stimulate discussion in this area.

\section{Author Contributions}

Muneaki Hikita wrote the manuscript, and Khalid Lafdi and Robyn L. Bradford reviewed and edited the final version.

\section{Conflicts of Interest}

The authors declare no conflict of interest.

\section{References}

1. Kroto, H.W.; Heath, J.R.; O’Brien, S.C.; Curl, R.F.; Smalley, R.E. C60: Buckminsterfullerene. Nature 1985, 318, 162-163.

2. Iijima, S. Helical microtubules of graphitic carbon. Nature 1991, 354, 56-58.

3. Novoselov, K.; Jiang, D.; Schedin, F.; Booth, T.; Khotkevich, V.; Morozov, S.; Geim, A. Two-dimensional atomic crystals. Proc. Natl. Acad. Sci. USA 2005, 102, 10451-10453.

4. Motojima, S.; Kawaguchi, M.; Nozaki, K.; Iwanaga, H. Preparation of coiled carbon fibers by catalytic pyrolysis of acetylene, and its morphology and extension characteristics. Carbon 1991, 29, 379-385.

5. Li, H.; Kang, Z.; Liu, Y.; Lee, S.-T. Carbon nanodots: Synthesis, properties and applications. J. Mater. Chem. 2012, 22, 24230-24253.

6. Zhang, M.; Nakayama, Y.; Pan, L. Synthesis of carbon tubule nanocoils in high yield using iron-coated indium tin oxide as catalyst. Jpn. J. Appl. Phys. 2000, 39, doi:10.1143/JJAP.39.L1242. 
7. Yang, S.; Chen, X.; Aoki, H.; Motojima, S. Tactile microsensor elements prepared from aligned superelastic carbon microcoils and polysilicone matrix. Smart Mater. Struct. 2006, 15, 687-694.

8. Hayashida, T.; Pan, L.; Nakayama, Y. Mechanical and electrical properties of carbon tubule nanocoils. Phys. B 2002, 323, 352-353.

9. Chang, N.-K.; Chang, S.-H. Determining mechanical properties of carbon microcoils using lateral force microscopy. IEEE Trans. Nanotechnol. 2008, 7, 197-201.

10. Motojima, S.; Noda, Y.; Hoshiya, S.; Hishikawa, Y. Electromagnetic wave absorption property of carbon microcoils in 12-110 GHz region. J. Appl. Phys. 2003, 94, 2325-2330.

11. Pan, L.; Hayashida, T.; Zhang, M.; Nakayama, Y. Field emission properties of carbon tubule nanocoils. Jpn. J. Appl. Phys. 2001, 40, 235-237.

12. Davis, W.; Slawson, R.; Rigby, G.R. An unusual form of carbon. Nature 1953, 171, doi:10.1038/171756a0.

13. Baker, R.; Barber, M.; Harris, P.; Feates, F.; Waite, R. Nucleation and growth of carbon deposits from the nickel catalyzed decomposition of acetylene. J. Catal. 1972, 26, 51-62.

14. Boehm, H. Carbon from carbon monoxide disproportionation on nickel and iron catalysts: Morphological studies and possible growth mechanisms. Carbon 1973, 11, 583-590.

15. Motojima, S.; Itoh, Y.; Asakura, S.; Iwanaga, H. Preparation of micro-coiled carbon fibres by metal powder-activated pyrolysis of acetylene containing a small amount of sulphur compounds. J. Mater. Sci. 1995, 30, 5049-5055.

16. Motojima, S.; Chen, Q. Three-dimensional growth mechanism of cosmo-mimetic carbon microcoils obtained by chemical vapor deposition. J. Appl. Phys. 1999, 85, 3919-3921.

17. Yang, S.; Chen, X.; Motojima, S. Morphology of the growth tip of carbon microcoils/nanocoils. Diam. Relat. Mater. 2004, 13, 2152-2155.

18. Li, D.; Pan, L.; Qian, J.; Liu, D. Highly efficient synthesis of carbon nanocoils by catalyst particles prepared by a sol-gel method. Carbon 2010, 48, 170-175.

19. Kanada, R.; Pan, L.; Akita, S.; Okazaki, N.; Hirahara, K.; Nakayama, Y. Synthesis of multiwalled carbon nanocoils using codeposited thin film of Fe-Sn as catalyst. Jpn. J. Appl. Phys. 2008, 47, 1949-1951.

20. Chen, X.; Motojima, S. Morphologies of carbon micro-coils grown by chemical vapor deposition. J. Mater. Sci. 1999, 34, 5519-5524.

21. Mukhopadhyay, K.; Porwal, D.; Ram, K.; Rao, K.U.B. Synthesis of carbon coiled micro/nano-structures in the absence of sulphurous promoter. J. Mater. Sci. 2007, 42, 379-383.

22. Yang, S.; Chen, X.; Kikuchi, N.; Motojima, S. Catalytic effects of various metal carbides and Ti compounds for the growth of carbon nanocoils (CNCs). Mater. Lett. 2008, 62, 1462-1465.

23. Ding, D.; Wang, J.; Dozier, A. Symmetry-related growth of carbon nanocoils from Ni-P based alloy particles. J. Appl. Phys. 2004, 95, 5006-5009.

24. Furuya, Y.; Hashishin, T.; Iwanaga, H.; Motojima, S.; Hishikawa, Y. Interaction of hydrogen with carbon coils at low temperature. Carbon 2004, 42, 331-335.

25. Okada, Y.; Takeuchi, K.; Yamanashi, H.; Ushijima, H. Formation of carbon whiskers by heating with a carbon dioxide laser. J. Mater. Sci. Lett. 1992, 11, 1715-1717. 
26. Kuzuya, C.; Hayashi, Y.; Motojima, S. Preparation of carbon micro-coils involving the decomposition of hydrocarbons using pact (plasma and catalyst technology) reactor. Carbon 2002, 40, 1071-1077.

27. Chen, X.; Yang, S.; Takeuchi, K.; Hashishin, T.; Iwanaga, H.; Motojiima, S. Conformation and growth mechanism of the carbon nanocoils with twisting form in comparison with that of carbon microcoils. Diam. Relat. Mater. 2003, 12, 1836-1840.

28. Qin, Y.; Jiang, X.; Cui, Z. Low-temperature synthesis of amorphous carbon nanocoils via acetylene coupling on copper nanocrystal surfaces at $468 \mathrm{~K}$ : A reaction mechanism analysis. J. Phys. Chem. B 2005, 109, 21749-21754.

29. Qin, Y.; Yu, L.; Wang, Y.; Li, G.; Cui, Z. Amorphous helical carbon nanofibers synthesized at low temperature and their elasticity and processablity. Solid State Commun. 2006, 138, 5-8.

30. Nitze, F.; Abou-Hamad, E.; Wågberg, T. Carbon nanotubes and helical carbon nanofibers grown by chemical vapour deposition on $\mathrm{C}_{60}$ fullerene supported $\mathrm{Pd}$ nanoparticles. Carbon 2011, 49 , 1101-1107.

31. Pan, L.; Hayashida, T.; Harada, A.; Nakayama, Y. Effects of iron and indium tin oxide on the growth of carbon tubule nanocoils. Phys. B 2002, 323, 350-351.

32. Pan, L.; Zhang, M.; Nakayama, Y. Growth mechanism of carbon nanocoils. J. Appl. Phys. 2002, 91, 10058-10061.

33. Okazaki, N.; Hosokawa, S.; Goto, T.; Nakayama, Y. Synthesis of carbon tubule nanocoils using Fe-In-Sn-O fine particles as catalysts. J. Phys. Chem. B 2005, 109, 17366-17371.

34. Yang, S.; Chen, X.; Katsuno, T.; Motojima, S. Controllable synthesis of carbon microcoils/nanocoils by catalysts supported on ceramics using catalyzed chemical vapor deposition process. Mater. Res. Bull. 2007, 42, 465-473.

35. Chen, X.; Yang, S.; Motojima, S.; Ichihara, M. Morphology and microstructure of twisting nano-ribbons prepared using sputter-coated fe-base alloy catalysts on glass substrates. Mater. Lett. 2005, 59, 854-858.

36. Sun, J.; Koós, A.A.; Dillon, F.; Jurkschat, K.; Castell, M.R.; Grobert, N. Synthesis of carbon nanocoil forests on $\mathrm{BaSrTiO}_{3}$ substrates with the aid of a sn catalyst. Carbon 2013, 60, 5-15.

37. Qi, X.; Zhong, W.; Yao, X.; Zhang, H.; Ding, Q.; Wu, Q.; Deng, Y.; Au, C.; Du, Y. Controllable and large-scale synthesis of metal-free carbon nanofibers and carbon nanocoils over water-soluble $\mathrm{Na}_{x} \mathrm{~K}_{y}$ catalysts. Carbon 2012, 50, 646-658.

38. Baker, R.T.K. Catalytic growth of carbon filaments. Carbon 1989, 27, 315-323.

39. Rostrup-Nielsen, J.R. Sulfur-passivated nickel catalysts for carbon-free steam reforming of methane. J. Catal. 1984, 85, 31-43.

40. Baker, R.T.K.; Harris, P.S.; Terry, S. Unique form of filamentous carbon. Nature 1975, 253, 37-39.

41. Audier, M.; Coulon, M. Kinetic and microscopic aspects of catalytic carbon growth. Carbon 1985, 23, 317-323.

42. Audier, M.; Oberlin, A.; Coulon, M. Study of biconic microcrystals in the middle of carbon tubes obtained by catalytic disproportionation of CO. J Cryst. Growth 1982, 57, 524-534.

43. Chen, X.; Saito, T.; Kusunoki, M.; Motojima, S. Three-dimensional vapor growth mechanism of carbon microcoils. J. Mater. Res. 1999, 14, 4329-4336. 
44. Chen, X.; Yang, S.; Motojima, S. Morphology and growth models of circular and flat carbon coils obtained by the catalytic pyrolysis of acetylene. Mater. Lett. 2002, 57, 48-54.

45. Chen, Y.; Liu, C.; Du, J.-H.; Cheng, H.-M. Preparation of carbon microcoils by catalytic decomposition of acetylene using nickel foam as both catalyst and substrate. Carbon 2005, 43, 1874-1878.

46. Wang, W.; Yang, K.; Gaillard, J.; Bandaru, P.R.; Rao, A.M. Rational synthesis of helically coiled carbon nanowires and nanotubes through the use of tin and indium catalysts. Adv. Mater. 2008, 20, 179-182.

47. Gohara, T.; Takei, K.; Arie, T.; Akita, S. In-situ optical microscopy observations of the growth of individual carbon nanocoils. J. Vac. Sci. Technol. B 2014, 32, doi:10.1116/1.4874004.

48. Hikita, M.; Lafdi, K. Synthesis and growth kinetics of carbon nanocoils using $\mathrm{Sn}-\mathrm{Fe}-\mathrm{O}$ xerogel film catalyst. Mater. Res. Express 2014, 1, doi:10.1088/2053-1591/1/3/035027.

49. Duan, H.; Liang, J.; Xia, Z. Synthetic hierarchical nanostructures: Growth of carbon nanofibers on microfibers by chemical vapor deposition. Mater. Sci. Eng. B 2010, 166, 190-195.

50. Kaneto, K.; Tsuruta, M.; Motojima, S. Electrical properties of carbon micro coils. Synth. Metals 1999, 103, 2578-2579.

51. Pierson, H.O. Handbook of Carbon, Graphite, Diamond, and Fullerenes: Properties, Processing, and Applications; Noyes Publications: Park Ridge, NJ, USA, 1993.

52. Fujii, M.; Matsui, M.; Motojima, S.; Hishikawa, Y. Magnetoresistance in carbon micro-coils annealed at various temperatures. J. Cryst. Growth 2002, 237, 1937-1941.

53. Katsuno, T.; Chen, X.; Yang, S.; Motojima, S. Relationship of a carbon microcoil and carbon microcoil tactile sensor element in electrical properties. Diam. Relat. Mater. 2007, 16, 1000-1003.

54. Kato, Y.; Adachi, N.; Okuda, T.; Yoshida, T.; Motojima, S.; Tsuda, T. Evaluation of induced electromotive force of a carbon micro coil. Jpn. J. Appl. Phys. 2003, 42, 5035-5037.

55. Chen, X.; Zhang, S.; Dikin, D.A.; Ding, W.; Ruoff, R.S.; Pan, L.; Nakayama, Y. Mechanics of a carbon nanocoil. Nano Lett. 2003, 3, 1299-1304.

56. Yonemura, T.; Suda, Y.; Tanoue, H.; Takikawa, H.; Ue, H.; Shimizu, K.; Umeda, Y. Torsion fracture of carbon nanocoils. J. Appl. Phys. 2012, 112, doi:10.1063/1.4758921.

57. Chen, X.; Motojima, S.; Iwanaga, H. Carbon coatings on carbon micro-coils by pyrolysis of methane and their properties. Carbon 1999, 37, 1825-1831.

58. Tang, N.; Yang, Y.; Lin, K.; Zhong, W.; Au, C.; Du, Y. Synthesis of plait-like carbon nanocoils in ultrahigh yield, and their microwave absorption properties. J. Phys. Chem. C 2008, 112, 10061-10067.

59. Motojima, S.; Chen, X.; Yang, S.; Hasegawa, M. Properties and potential applications of carbon microcoils/nanocoils. Diam. Relat. Mater. 2004, 13, 1989-1992.

60. Chen, X.; Yang, S.; Sawada, N.; Motojima, S. The design and performance of tactile/proximity sensors made of carbon microcoils. In Smart Sensors and Sensing Technology; Springer: Berlin, Germany, 2008; pp. 251-261.

61. Yoshimura, K.; Nakano, K.; Miyake, T.; Hishikawa, Y.; Motojima, S. Effectiveness of carbon microcoils as a reinforcing material for a polymer matrix. Carbon 2006, 44, 2833-2838.

62. Morohashi, H.; Nishida, Y.; Takahashi, Y.; Fujiki, K.; Yamauchi, T.; Tsubokawa, N.; Motojima, S. Grafting of polymers onto carbon microcoil surface by ligand-exchange reaction of ferrocene moieties of polymer with polycondensed aromatic rings of the surface. Polym. J. 2006, 39, 175-180. 
63. Morohashi, H.; Takahashi, Y.; Nishida, Y.; Fujiki, K.; Yamauchi, T.; Tsubokawa, N.; Motojima, S. Grafting of polymers onto carbon microcoil by use of carboxyl groups on the surface and electric properties of conductive composite prepared from silicone rubber with the polymer-grafted carbon microcoil. Polym. J. 2007, 39, 404-410.

64. Bi, H.; Kou, K.-C.; Ostrikov, K.K.; Yan, L.-K.; Wang, Z.-C. Microstructure and electromagnetic characteristics of ni nanoparticle film coated carbon microcoils. J. Alloys Compd. 2009, 478, 796-800.

65. Bi, H.; Kou, K.; Rider, A.; Ostrikov, K.; Wu, H.; Wang, Z. Low-phosporous nickel-coated carbon microcoils: Controlling microstructure through an electroless plating process. Appl. Surf. Sci. 2009, $255,6888-6893$.

66. Hikita, M.; Cao, L.; Lafdi, K. Optical properties of carbon microcoils. Appl. Phys. Lett. 2014, 104, doi:10.1063/1.4863501.

67. Motojima, S.; Suzuki, T.; Noda, Y.; Hiraga, A.; Iwanaga, H.; Hashishin, T.; Hishikawa, Y.; Yang, S.; Chen, X. Preparation of $\mathrm{TiO}_{2}$ microcoils from carbon microcoil templates using a sol-gel process. Chem. Phys. Lett. 2003, 378, 111-116.

68. Qin, Y.; Kim, Y.; Zhang, L.; Lee, S.-M.; Yang, R.B.; Pan, A.; Mathwig, K.; Alexe, M.; Gösele, U.; Knez, M. Preparation and elastic properties of helical nanotubes obtained by atomic layer deposition with carbon nanocoils as templates. Small 2010, 6, 910-914.

69. Rakhi, R.; Cha, D.; Chen, W.; Alshareef, H. Electrochemical energy storage devices using electrodes incorporating carbon nanocoils and metal oxides nanoparticles. J. Phys. Chem. C 2011, 115, 14392-14399.

70. Rakhi, R.; Chen, W.; Alshareef, H. Conducting polymer/carbon nanocoil composite electrodes for efficient supercapacitors. J. Mater. Chem. 2012, 22, 5177-5183.

71. Nitze, F.; Mazurkiewicz, M.; Malolepszy, A.; Mikolajczuk, A.; Kędzierzawski, P.; Tai, C.-W.; Hu, G.; Kurzydłowski, K.J.; Stobinski, L.; Borodzinski, A. Synthesis of palladium nanoparticles decorated helical carbon nanofiber as highly active anodic catalyst for direct formic acid fuel cells. Electrochim. Acta 2012, 63, 323-328.

72. Suda, Y.; Kaida, S.; Ozaki, M.; Shimizu, Y.; Okabe, Y.; Tanoue, H.; Takikawa, H.; Ue, H.; Shimizu, K. In Use of Carbon Nanocoil as a Catalyst Support in Direct Methanol Fuel Cell. In Proceedings of the IRAGO Conference 2013, Tahara, Japan, 24-25 October 2013.

(C) 2014 by the authors; licensee MDPI, Basel, Switzerland. This article is an open access article distributed under the terms and conditions of the Creative Commons Attribution license (http://creativecommons.org/licenses/by/4.0/). 